\title{
Сравнительный анализ разделения платины (IV) и палладия (II) при различных вариантах градиентного элюирования
}

И. С. Рудик ${ }^{1,2}$, О. Н. Катасонова, к. х. н.', Т. А. Марютина, д.х. н. ${ }^{1}$, Б. Я. Спиваков, д.х.н. ${ }^{1}$

удК 543.054

Предложены две схемы экстракционного разделения платины (IV) и палладия (II) из хлоридных растворов во вращающихся спиральных колонках (ВСК) - градиентное разделение вследствие смены концентрации элюента в подвижной фазе и за счет создания градиента концентрации экстрагента в неподвижной фазе. В качестве неподвижной фазы в ВСК выбран реагент класса четвертичных аммониевых оснований - хлорид метилтриалкиламмония (МТАA). Исследовано поведение Pd(II) иPt(IV) при их совместном присутствии в хлоридных растворах в зависимости от концентрации хлорид-иона, кислотности раствора и концентрации экстрагента. Показано, что создание градиента концентрации экстрагента в неподвижной фазе позволяет добиться полного разделения металлов и получить выделяемые фракции платины и палладия с чистотой более 99,90\%.

Ключевые слова: платиновые металлы, экстракция, вращающиеся спиральные колонки, градиентное разделение, хлорид метилтриалкиламмония

Two schemes for the extraction separation of platinum (IV) and palladium (II) from chloride solutions in rotating coiled columns (RCC) are proposed - gradient separation due to a change in the concentration of the eluent in the mobile phase and due to the creation of a gradient of the concentration of extractant in the stationary phase held in the column. A reagent of the quaternary ammonium base class, methyltrialkylammonium chloride (MTAA), was chosen as the stationary phase in the RCC. The behavior of $\mathrm{Pd}(\mathrm{II})$ and $\mathrm{Pt}(\mathrm{IV})$ with their joint presence in chloride solutions was studied depending on the concentration of chloride ion, the acidity of the solution, and the concentration of extractant. It was shown that creating a concentration gradient of the extractant in the stationary phase makes it possible to achieve complete separation of metals and to obtain separated fractions of platinum and palladium with a purity of more than $99,90 \%$.

Keywords: platinum metals, solvent extraction, rotating coiled columns, gradient separation, methyltrialkylammonium chloride 
Несмотря на интенсивное развитие инструментальных методов анализа, остается актуальной задача разработки новых способов пробоподготовки (выделения, концентрирования и разделения) при определении платиновых металлов (ПМ) в полученных при переработке техногенного сырья технологических растворах с высокой кислотностью и значительной концентрацией хлорид-ионов. Для экстракционных методов пробоподготовки характерны высокая селективность, обеспечивающая полноту разделения и получения чистых фракций целевых металлов, эффективность концентрирования из растворов с низкими содержаниями выделяемых компонентов, возможность регенерации используемых экстрагентов [1].

В ГЕОХИ РАН для экстракции и разделения различных веществ используется планетарная центрифуга, оснащенная вращающимися спиральными колонками (BCK) [2]. ВСК представляет собой тефлоновую трубку, намотанную в виде спирали на жесткий сердечник. Во время работы колонка вращается вокруг своей оси и одновременно вокруг центральной оси планетарной центрифуги (рис. 1).

Благодаря особенностям конструкции ВСК, одна из несмешивающихся фаз двухфазной жидкостной системы удерживается в приборе под действием гравитационных и центробежных сил (неподвижная фаза), в то время как вторая фаза (подвижная) прокачивается через нее. Объем неподвижной фазы, удерживаемый в ВСК, зависит от гидродинамических условий процесса экстракции (скорости прокачивания подвижной фазы F и скорости вращения колонки $\omega)$ и от физико-химических свойств двухфазных жидкостных систем (межфазного натяжения, разностей плотности и вязкости фаз) [3]. Экстракция в BCK характеризуется широким выбором экстракционных систем и реагентов, легкостью перехода от одной распределительной системы к другой, высокой эффективностью разделения, возможностью реализации многоступенчатой экстракции и концентрирования следовых количеств веществ, отсутствием сорбента для удерживания неподвижной фазы, высокой препаративной емкостью [4]. Сегодня ряд планетарных центрифуг, основным узлом которых является ВСК, производится на коммерческой основе, их объем варьирует от нескольких миллилитров до 50 л [5].

Для экстракции металлов платиновой группы (ПМ) применяется широкий ряд экстрагентов: соли четвертичных аммониевых оснований [6-8], амины [9-11], азотсеро- и фосфорсодержащие экстрагенты [12-14]; сульфооксиды [15, 16], в последние годы предложено большое количество новых реагентов и различных сочетаний - бинарных соединений, высокоспецифичных ионных жидкостей, макроциклических экстрагентов и др. [17-20]. Однако до сих пор остается нерешенной задача полного извлечения и чистоты индивидуальных фракций металлов, полученных при экстракционном разделении ПМ.

В работе рассмотрены два способа реализации градиентного многоступенчатого экстракционного разделения платины (IV) и палладия (II) из хлоридных растворов в ВСК. В первом случае извлечение металлов из органической фазы экстрагента (неподвижная фаза) проводили путем изменения состава элюента (подвижная фаза). Второй способ основывался на создании градиента концентрации самого экстрагента в неподвижной фазе благодаря особому способу заполнения ВСК. Следует отметить, что ни один другой динамический метод разделения не позволяет формировать градиент концентрации экстрагента в растворителе (неподвижной фазе) в ходе процесса разделения. Использование термина "градиентное элюирование" в данном случае имеет принципиальное отличие от традиционной схемы, при которой разделение компонентов с близкими свойствами происходит за счет смены концентрации элюента (подвижная фаза). В нашем случае градиентное элюирование - следствие изменения концентрации экстрагента в растворителе (неподвижной фазе), которое достигается удерживанием внутри ВСК отдельных порций растворителя и экстрагента, а затем их последующим перемешиванием.

Цель работы - сравнительный анализ эффективности применения двух способов реализации градиентного элюирования на примере разделения Pt(IV) и $\mathrm{Pd}(\mathrm{II})$ из модельного хлоридного раствора в ВСК.

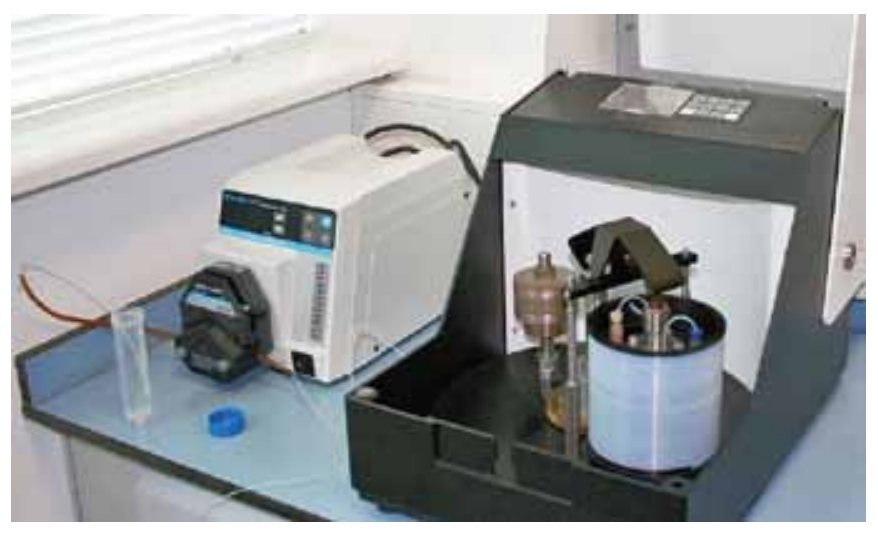

Puc. 1. Фотография планетарной центрифуги с ВСК (Институт аналитического приборостроения, СанктПетербург) 


\section{Экспериментальная часть}

Растворы и реагенты

В качестве экстрагента использовали раствор МТАА (метилтриалкиламмоний хлорид, Adogen 464, 98\%, MERCK, Германия) в толуоле (ос.ч.).

Модельные растворы ПМ готовили из их солей $\mathrm{PdCl}_{2}$ (ч.), $\mathrm{Na}_{2}\left[\mathrm{PtCl}_{6}\right] \cdot 6 \mathrm{H}_{2} \mathrm{O}$ (ч.), в соответствии с методикой [21]. Концентрация ПМ в хлоридных растворах (1-6 M HCl + 30 г/л и 90 г/л $\left.\mathrm{Cl}^{-}\right)$составляла 250 мкг/мл $\mathrm{Pd}(\mathrm{II})$ и 50 мкг/мл $\mathrm{Pt}(\mathrm{IV})$. Хлоридный фон моделировали добавлением в раствор соли хлорида натрия.

Для реэкстракции ПМ из органической фазы применяли водные растворы $\mathrm{HCl}$, тиомочевины $\left(\mathrm{NH}_{2} \mathrm{CSNH}_{2}\right), \mathrm{HNO}_{3}, \mathrm{H}_{2} \mathrm{SO}_{4}, \mathrm{HClO}_{4}, \mathrm{NaOH}, \mathrm{NH}_{4} \mathrm{OH}$, аммиачный буферный раствор. Все реагенты соответствовали квалификации х.ч.

\section{Аппаратура}

Экстракцию в статическом режиме проводили с помощью лабораторного механического шейкера модели StuartSSL2 (Stuart, Великобритания). Для разделения фаз использовали центрифугу CM-6MT (ЕLMI, Латвия).

Концентрирование и разделение ПМ в динамическом режиме проводили в планетарной центрифуге "Спринг-3М", оснащенной ВСК (Институт аналитического приборостроения, Санкт-Петербург). Внутренний диаметр тефлоновой трубки ВСК составляет 1,6 мм, а толщина стенки - 0,75 мм. Внутренний объем колонки и каждого из подводящих путей 16 и 2 мл соответственно. Растворы ПМ, экстрагентов и реэкстрагентов подавались в ВСК с помощью перистальтического насоса Masterflex (Великобритания).

\section{Техника эксперимента}

Экстракцию и реэкстракцию ПМ в статическом режиме проводили при комнатной температуре в полипропиленовых пробирках объемом 50 мл при соотношении водной и органической фаз Vв: Vo=1:1, общий объем которых не превышал 20 мл. Время контакта фаз составляло 15 мин. Водную фазу анализировали на содержание металлов.

Эксперименты по разделению ПМ в динамическом режиме методом ступенчатого элюирования ВСК проводили по следующей схеме, добавляя в колонку последовательно 4 мл холостого раствора $\left(1 \mathrm{M} \mathrm{HCl}+30\right.$ г/л $\left.\mathrm{Cl}^{-}\right), 10$ мл раствора MTАА в толуоле, 6 мл холостого раствора. Затем колонку приводили в движение и вращали с постоянной скоростью $\omega=600$ об / мин, удерживая неподвижную фазу (экстрагент) в колонке. Подвижную фазу (водные растворы
ПМ или реэкстрагенты) прокачивали через колонку с постоянной скоростью потока $F=0,65$ мл/мин. Каждые 5 мл подвижной фазы отбирали в отдельные фракции для анализа на содержание металлов.

При создании градиента концентрации реагента в неподвижной фазе колонку заполняли следующим образом: 5 мл холостого раствора $\left(1 \mathrm{M} \mathrm{HCl}+30\right.$ г/л $\left.\mathrm{Cl}^{-}\right)-4$ мл толуола -4 мл холостого раствора - 4 мл 0,05 М МТАА в толуоле - 3 мл холостого раствора. Скорость вращения ВСК $\omega=600$ об $/$ мин, скорость прокачивания подвижной фазы $F=0,65$ мл / мин. Каждые 5 мл подвижной фазы анализировали на содержание металлов.

\section{Определение}

Концентрации металлов в растворе до и после экстракции/реэкстракции определяли методом массспектрометрии с индуктивно связанной плазмой (МС-ИСП) на масс-спектрометре Agilent 7900 (Agilent Technologies, США), снабженном двухходовой стеклянной распылительной камерой, стеклянным распылителем MicroMist и кварцевой горелкой.

\section{Результаты и обсуждение}

\section{Влияние кислотности раствора}

и хлоридного фона

Ранее [22] было показано, что раствор МТАА практически количественно извлекает палладий и платину из солянокислых растворов различной концентрации (1-6 M). Однако технологические аффинажные растворы, как правило, характеризуются избытком хлорид-ионов.

На рис. 2 представлены результаты исследования зависимости степени извлечения палладия (II) и платины (IV) от хлоридного фона модельного раствора. В ходе экспериментальной работы было выявлено, что выделение Pd(II) в фазу экстрагента снижается при повышении кислотности раствора, а также избытка $\mathrm{Cl}^{-}$-ионов. При этом степень извлечения (E) платины (IV) остается практически неизменной. Причина в том, что комплексы платины $\left[\mathrm{PtCl}_{6}\right]^{2-}$ способны образовывать более прочные связи с аминными группами экстрагента по сравнению с $\left[\mathrm{PdCl}_{4}\right]^{2-}[1,6]$. При увеличении концентрации хлорид-иона в растворе наблюдается подавление экстракции палладия из-за конкуренции между хлорид-ионом и хлорокомплексом металла за молекулу экстрагента. Количественное извлечение ПМ из солянокислых и хлоридных растворов в 0,05 М МТАА в толуоле наблюдается при концентрации соляной кислоты - 1 М и составляет для палладия 99,4-99,1\%, для платины - 99,99-99,90\%. 

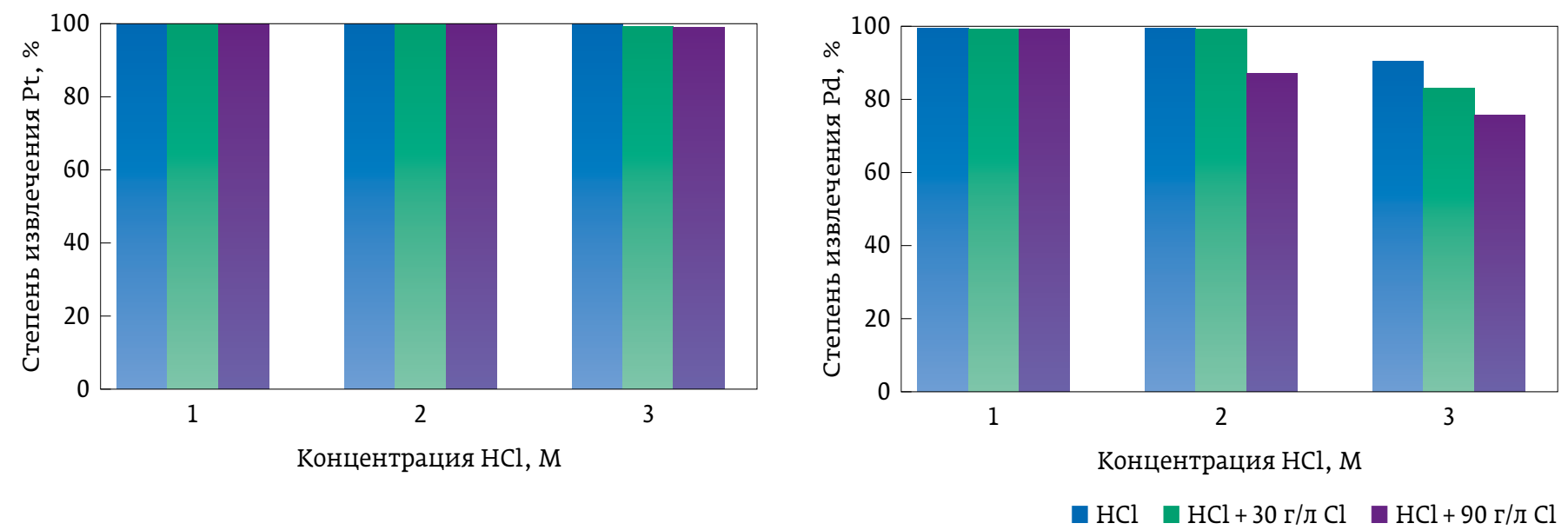

Puc. 2. Зависимость степени извлечения Pt(IV) и Pd(II) в 0,05 М МТАА в толуоле от концентрации соляной кислоты и хиоридного фона

Реэкстракция платиновых металлов

Реэкстракция платины (IV) и палладия (II) из органической фазы была изучена с использованием различных водных растворов: $\mathrm{NH}_{2} \mathrm{CSNH}_{2}$ в $\mathrm{HCl}, \mathrm{H}_{2} \mathrm{SO}_{4}$, $\mathrm{HNO}_{3}, \mathrm{NH}_{4} \mathrm{OH}, \mathrm{NaOH}$, аммиачный буферный раствор (табл. 1). Согласно полученным данным, для реэкстракции $\mathrm{Pt}(\mathrm{IV})$ и $\mathrm{Pd}(\mathrm{II})$ наиболее эффективно использование солянокислых растворов тиомочевины. При этом степень извлечения ПМ существенно зависит от концентрации тиомочевины: палладий (II) реэкстрагируется при более низких концентрациях $\left(0,01 \mathrm{M} \mathrm{NH}_{2} \mathrm{CSNH}_{2}\right.$ в 0,5 M HCl) и может быть отделен от платины (IV), для выделения которой требуются более концентрированные растворы тиомочевины $\left(1 \mathrm{M} \mathrm{NH}_{2} \mathrm{CSNH}_{2}\right.$ в $\left.0,5 \mathrm{M} \mathrm{HCl}\right)$. Растворы хлорной и азотной кислот не позволяют селективно разделить палладий и платину - оба металла вымываются из органической фазы одновременно в реэкстрагент. Примесь платины во фракции палладия при использовании растворов $\mathrm{NH}_{4} \mathrm{OH}, \mathrm{NaOH}$, а также аммиачного буферного раствора в несколько раз выше по сравнению с раствором 0,01 $\mathrm{M} \mathrm{NH}_{2} \mathrm{CSNH}_{2}$ в $0,5 \mathrm{M} \mathrm{HCl}$.
Разделение платины (IV) и палладия (II) с применением градиента концентрации элюента в подвижной фазе

Схема разделения платины и палладия в ВСК классическим способом градиентного элюирования (изменение концентрации элюента) опробована на модельном хлоридном растворе $-1 \mathrm{M} \mathrm{HCl}+30$ г/ л $\mathrm{Cl}^{-}$. В качестве неподвижной фазы использовали $0,05 \mathrm{M}$ раствор МТАА в толуоле, платину и палладий последовательно реэкстрагировали растворами тиомочевины разной концентрации (рис. 3). На выходе из колонки получены отдельные водные фракции платины (IV) и палладия (II). Однако индивидуальные фракции выделенных металлов содержат примеси друг друга, при этом степень извлечения платины по отношению к исходному количеству составила $87 \%$ (табл. 2).

Разделение платины (IV) и палладия (II) с формированием градиента концентрации экстрагента в неподвижной фазе Создание градиента концентрации экстрагента в ВСК дает возможность для разделения элементов

Таблица 1. Реэкстракция Pt(IV) и Pd(II) из 0,05 М MTAА в толуоле при использовании различных растворов

\begin{tabular}{|c|c|c|c|c|c|c|c|c|}
\hline \multirow[t]{3}{*}{$\Pi \mathrm{M}$} & \multicolumn{8}{|c|}{ Степень извлечения из органической фазы, \% } \\
\hline & \multicolumn{8}{|c|}{ Реэкстрагент } \\
\hline & $\begin{array}{c}2 \mathrm{M} \\
\mathrm{HNO}_{3}\end{array}$ & $\begin{array}{c}2 \mathrm{M} \\
\mathrm{H}_{2} \mathrm{SO}_{4}\end{array}$ & $\begin{array}{c}2 \mathrm{M} \\
\mathrm{HClO}_{4}\end{array}$ & $\begin{array}{c}2 \mathrm{M} \\
\mathrm{NaOH}\end{array}$ & $\begin{array}{c}2 \mathrm{M} \\
\mathrm{NH}_{4} \mathrm{OH}\end{array}$ & $\begin{array}{c}\text { аммиачный } \\
\text { буферный } \\
\text { p-p }\end{array}$ & $\begin{array}{c}0,01 \mathrm{M} \\
\mathrm{NH}_{2} \mathrm{CSNH}_{2} \\
\text { в } 0,5 \mathrm{M} \mathrm{HCl}\end{array}$ & $\begin{array}{c}1 \mathrm{M} \\
\mathrm{NH}_{2} \mathrm{CSNH} \mathrm{H}_{2} \\
\text { в } 0,5 \mathrm{M} \mathrm{HCl}\end{array}$ \\
\hline Pd & 25 & 1,3 & 51 & 26 & 96 & 62 & 58 & 80 \\
\hline Pt & 27 & 0,8 & 62 & 4 & 8 & 14 & 0,5 & 56 \\
\hline
\end{tabular}




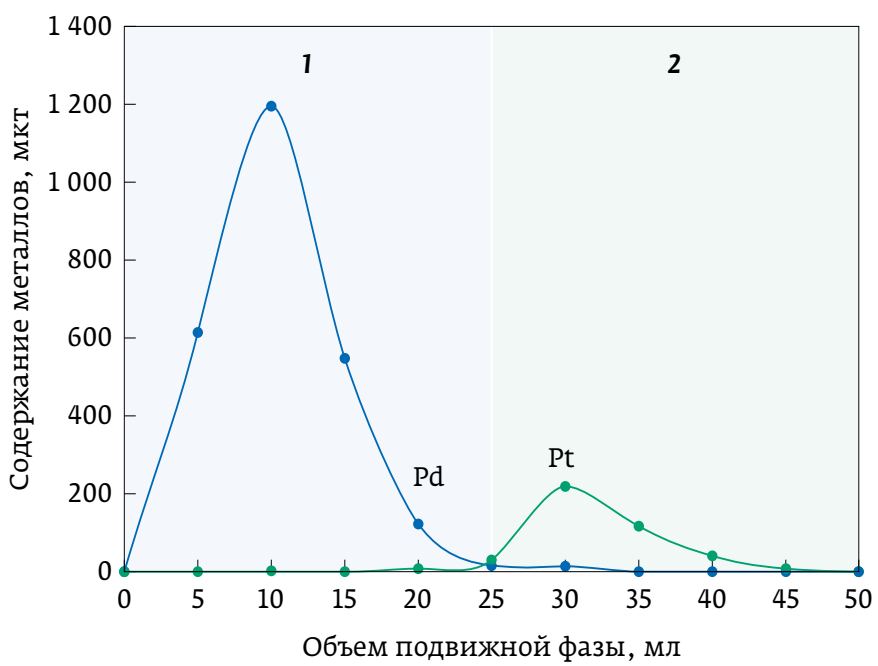

Puc. 3. Разделение Pd(II) и Pt(IV) в ВСК в условиях градиента концентрации элюента в подвижной фазе.

Исходный раствор: 10 мл $1 \mathrm{M} \mathrm{HCl}+30$ г/^ $\mathrm{Cl}^{-}$,

$[\mathrm{Pd}]_{\text {uсx }}=250$ мкг / мл, $[\mathrm{Pt}]_{\mathrm{ucx}}=50$ мкг $/$ мл.

Неподвижная фаза: 10 мл 0,05 М раствора МТАА в толуоле; подвижная фаза: 1-25 мл 0,01 $\mathrm{M} \mathrm{NH}_{2} \mathrm{CSNH}_{2}$ в 0,5 $\mathrm{MHCl}$,

2-25 $\mathrm{M} \wedge 7 \mathrm{M} \mathrm{NH}_{2} \mathrm{CSNH}_{2}$ в 0,5 $\mathrm{M} \mathrm{HCl}$

с близкими свойствами, особенно в случае явной зависимости их коэффициентов распределения от концентрации экстрагента в растворителе. Градиент концентрации экстрагента в неподвижной фазе возникает при перемешивании порций растворителя и экстрагента по длине ВСК во время ее вращения при определенной скорости прокачивания подвижной фазы, включая ввод анализируемого раствора.

На начальном этапе исследовано влияние концентрации экстрагента МТАА в толуоле на степень извлечения $\mathrm{Pt}(\mathrm{IV})$ и $\mathrm{Pd}(\mathrm{II})$ в $1 \mathrm{M} \mathrm{HCl}+30$ г/ л $\mathrm{Cl}^{-}$(рис. 4).

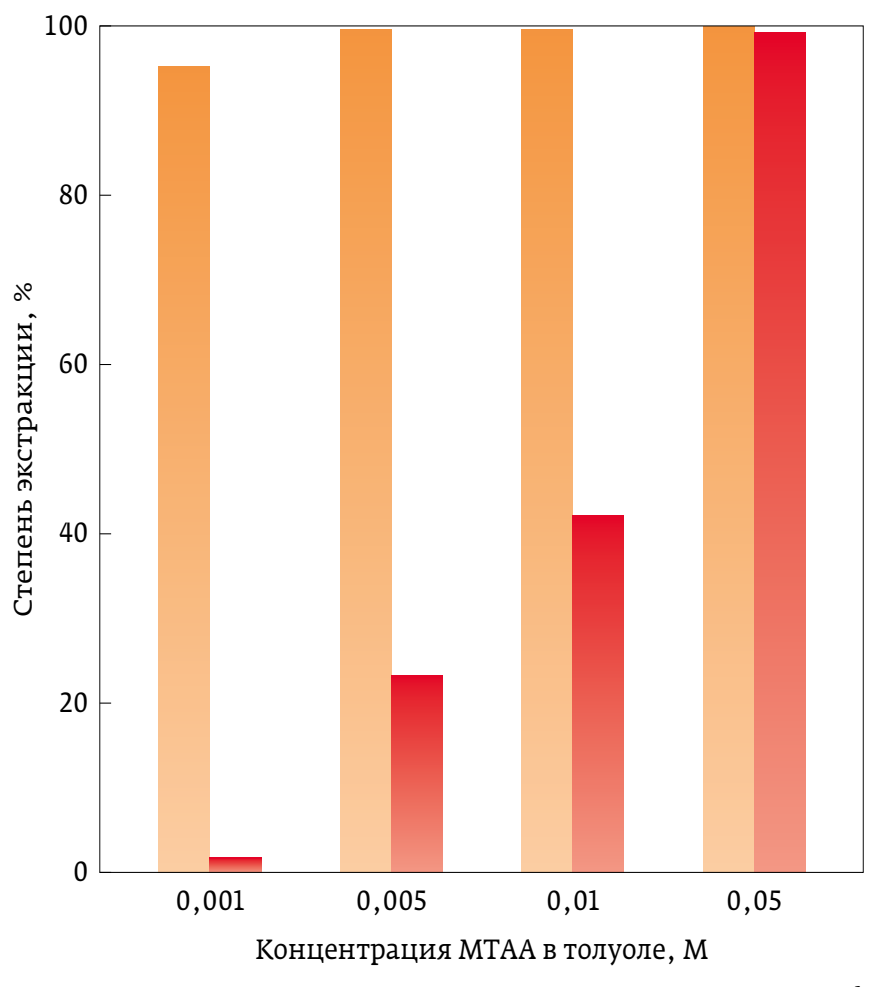

Puc. 4. Зависимость степени извлечения Pt(IV) и Pd(II) из $7 \mathrm{M} \mathrm{HCl}+30$ г/ / $\mathrm{Cl}^{-}$от концентрации MTAA

Полученные результаты позволили предположить возможность экстракционного разделения $\mathrm{Pt}(\mathrm{IV})$ и $\mathrm{Pd}(\mathrm{II})$ в BCK в условиях создания градиента концентрации реагента в неподвижной фазе. Предварительно исследовали закономерности образования внутри ВСК градиента концентрации МТАА в толуоле с подвижной фазой $1 \mathrm{M} \mathrm{HCl}$. Доказано, что при низких значениях $\omega$ (до 700 об/мин) и $F$ (до 1,0 мл / мин) образуется устойчивый градиент

Таблица 2. Разделение Pt(IV) и Pd(II) из модельного хлоридного раствора в ВСК. Неподвижная фаза - 0,05 М раствор МТАА в толуоле, элюэнты - растворы тиомочевины разной концентрации

\begin{tabular}{|c|c|c|c|c|c|c|c|c|c|}
\hline \multirow[t]{3}{*}{ Пм } & \multirow{3}{*}{$\begin{array}{c}\begin{array}{c}\text { Исходный } \\
\text { раствор } \\
(V=10 \text { мл })\end{array} \\
m_{M}, \text { мкг }\end{array}$} & \multirow{2}{*}{\multicolumn{2}{|c|}{$\begin{array}{c}\text { 0,05 М МТАA } \\
\text { в толуоле } \\
\text { (V=10 мл) }\end{array}$}} & \multicolumn{4}{|c|}{ Растворы элюентов } & \multirow{3}{*}{$E^{* *}$} & \multirow{3}{*}{$\begin{array}{c}\text { Примесь, } \\
\%\end{array}$} \\
\hline & & & & \multicolumn{2}{|c|}{$\begin{array}{c}0,01 \mathrm{M} \mathrm{NH}_{2} \mathrm{CSNH}_{2} \text { в } 0,5 \mathrm{M} \mathrm{HCl} \\
(V=25 \mathrm{M})\end{array}$} & \multicolumn{2}{|c|}{$\begin{array}{c}1 \mathrm{M} \mathrm{NH}_{2} \mathrm{CSNH}_{2} \text { в } 0,5 \mathrm{M} \mathrm{HCl} \\
(V=25 \mathrm{~m})\end{array}$} & & \\
\hline & & $m_{M}$, МКг & $E^{*}, \%$ & $m_{M}, M K r$ & $E^{*}, \%$ & $m_{M}$, мкг & $E^{* *}, \%$ & & \\
\hline $\mathrm{Pd}$ & 2500 & 2500 & 100 & 2475 & 99 & 25 & 1 & 100 & $0,5(\mathrm{Pt})$ \\
\hline $\mathrm{Pt}$ & 500 & 500 & 100 & 13,5 & 2,7 & 421,5 & 84,3 & 87 & $5,5(P d)$ \\
\hline
\end{tabular}

* Степень извлечения в органическую фазу.

** Степень извлечения в водную фазу.

*** Степень извлечения относительно концентрации компонента в исходном растворе. 
концентрации МТАА внутри колонки, сохраняющийся достаточно длительное время [23]. На рис. 5 и в табл. 3 представлены результаты разделения ПМ при условии градиента концентрации экстрагента в ВСК.

Из представленных данных видно, что создание градиента концентрации реагента в неподвижной фазе позволило добиться разделения платины и палладия, которые извлекаются из колонки отдельными хорошо разрешенными пиками без взаимных примесей в индивидуальных фракциях. Уменьшение концентрации МТАА в органической фазе приводит к изменению коэффициентов распределения палладия от 110 до 0,014 при практически неизменных коэффициентах распределения платины в процессе экстракции, что позволяет реэкстрагировать палладий без применения комплексообразующих реагентов - он вымывается из колонки на стадии концентрирования платины. Платина элюируется из колонки при пропускании через нее раствора тиомочевины.

Таким образом, использование ВСК позволяет проводить экстракцию и реэкстракцию ПМ из хлоридных растворов в динамическом режиме, что делает метод удобным для практического применения в качестве инструмента пробоподготовки. Для разделения платины и палладия предложены два способа градиентного элюирования, которые реализуются как путем изменения состава подвижной фазы - прокачивания через ВСК разных концентраций раствора тиомочевины в соляной кислоте, так и созданием градиента концентраций экстрагента в растворителе (МТАА в толуоле). Классический способ градиентного разделения платиновых металлов в предложенной системе не позволяет добиться полного разделения металлов. Следует отметить, что применение ВСК дает уникальную возможность изменения состава

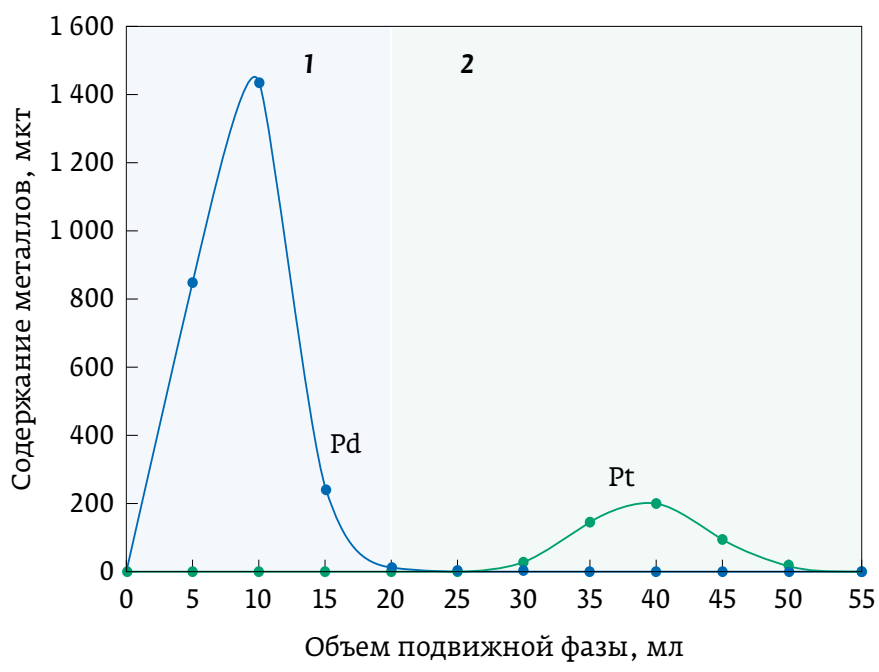

Puc. 5. Разделение Pt(IV) и Pd(II) в ВСК при формировании градиента концентрации МТАА в неподвижной фазе. Исходный раствор: 10 мп $1 \mathrm{M} \mathrm{HCl}+302 / \wedge \mathrm{Cl}^{-}$,

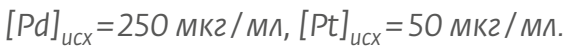

Неподвижная фаза: МТАА в толуоле;

подвижная фаза: 1-20 мп $7 \mathrm{M} \mathrm{HCl}+30$ 2/ $/ \mathrm{Cl}^{-}$,

2-25 $\mathrm{M} \wedge 1 \mathrm{M} \mathrm{NH}_{2} \mathrm{CSNH}_{2}$ в $0,5 \mathrm{M} \mathrm{HCl}$

неподвижной фазы во время процесса экстракционного разделения ПМ. Создание градиента концентрации реагента в органической фазе позволяет количественно извлечь платину в раствор тиомочевины, а также получить на выходе фракцию палладия (II) без помощи реэкстрагента.

\section{Литература}

1. Аналитическая химия металлов платиновой группы // Сб. обзорных статей / Сост. и ред.: Золотов Ю.А., Варшал Г. М., Иванов В. М.; изд. 2-е, стереотипное. М.: КомКнига, 2005. 592 с.

Таблица 3. Разделение Pt(IV) и Pd(II) из модельного хлоридного раствора в ВСК с использованием градиента концентрации МТАА в толуоле в качестве неподвижной фазы

\begin{tabular}{|c|c|c|c|c|c|c|c|c|c|}
\hline \multirow[t]{3}{*}{$\Pi M$} & \multirow{3}{*}{$\begin{array}{c}\text { Исходный } \\
\text { раствор } \\
\text { (V=10 мл) }\end{array}$} & \multirow{2}{*}{\multicolumn{2}{|c|}{$\begin{array}{c}\text { МТАА в толуоле } \\
\text { (V=8 мл) }\end{array}$}} & \multicolumn{4}{|c|}{ Растворы элюентов } & \multirow{3}{*}{ E } & \multirow{3}{*}{$\begin{array}{c}\text { Примесь, } \\
\%\end{array}$} \\
\hline & & & & \multicolumn{2}{|c|}{$\begin{array}{c}1 \mathrm{M} \mathrm{HCl}+30 г / л \mathrm{Cl}^{-} \\
(V=20 \mathrm{мл})\end{array}$} & \multicolumn{2}{|c|}{ 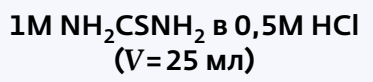 } & & \\
\hline & & $m_{M}$, мкг & $E$ & $m_{M}$, Мкг & $E^{* *}, \%$ & $m_{M}$, мкг & $E^{* \infty}, \%$ & & \\
\hline $\mathrm{Pd}$ & 2500 & 2500 & 100 & 2500 & 100 & 0 & 0 & 100 & $0(P t)$ \\
\hline Pt & 500 & 500 & 100 & 0 & 0 & 499 & 99,8 & 99,8 & $0(P d)$ \\
\hline
\end{tabular}

* Степень извлечения в органическую фазу.

** Степень извлечения в водную фазу.

*** Степень извлечения относительно концентрации компонента в исходном растворе. 
2. Марютина Т.А., Федотов П.С. Жидкостная хроматография со свободной неподвижной фазой в элементном анализе: от нефти до особо чистых веществ // Журн. аналит. химии. 2019. Т. 74. № 3. С. 201-210.

3. Федотов П. С., Кронрод В. А., Марютина Т. А., Спиваков Б. Я. Моделирование механизма удерживания неподвижной фазы во вращающейся спиральной колонке: гидрофобные жид костные системы // Журн. аналит. химии. 2002. Т. 57. № 1. C. 30-37.

4. Countercurrent Chromatography: The Support-Free Liquid Stationary Phase // Comprehensive Analytical Chemistry (Ed.: Berthod A.). Amsterdam: Elsevier. 2002. V. 38.

5. Satherland Y., Hewitson P., Ignatova S. New 18-l process-scole counter-current chromatohraghy // Journal of Chromatograghy A. 2009. V. 1216. P. 4701-4205.

6. Nguyen T.N., Sonu C.H., Lee M.S. Separation of platinum(IV) and palladium(II) from concentrated hydrochloric acid solution by mixtures of amines with neutral extractants // Journal of Industrial and Engineering Chemistry. 2015. V. 32. P. 238-245.

7. Lee J-Y, J. Kumar R., Kim J-S, Kim D-J., Yoon H-S. Extraction and separation of $\mathrm{Pt}(\mathrm{IV}) / \mathrm{Rh}$ (III) from acidic chloride solutions using Aliquat 336 // Journal of Industrial and Engineering Chemistry. 2009. V. 15. P. 359-364.

8. Hoh Y.C., Chuang W.S., Yueh P.S. The Extraction of Platinum from Pt(II) Chloride Solution by a Quaternary Ammonium Compound // J. Chem. Tech. Biotechnol. 1985. V. 35A. P. 41-47.

9. Pasdar H., Saghavaz B. H., Fallah Z., Shahi M., Davallo M. Liquid liquid extraction of palladium (II) in acids chloride solution using tri-n-octylamine // ASRJETS. 2017. V. 38. No. 1. P. 258-264.

10. Jaree A., Khunphakdee N. Separation of concentrated platinum(IV) and rhodium(III) in acidic chloride solution via liquid-liquid extraction using tri-octylamine// Journal of Industrial and Engineering Chemistry. 2011. V. 17. P. 243-247.

11. Mirza M.Y. Studies on the extraction of platinum metals with triiso-octylamine from hydrochloric and hydrobromic acid: separation and determination of gold, palladium and platinum // Talanta. 1980. V. 27(2). P. 101-106.

12. Costa M.C., Assunção A., Rosa da Costa A.M., Nogueira C., Paiva A.P. Liquid-liquid extraction of platinum from chloride media by N, N-dimetyl-N, N-dicyclohexyltetradecyl-malonamide // Solvent Extration and Ion Exchange. 2013. V. 31. P. 12-23.

13. Ortet O., Paiva A.P. Development of tertiary thioamide derivatives to recover palladium(II) from simulated complex chloride solutions // Hydrometallurgy. 2015. V. 151. P. 33-41.

14. Cieszynska A., Wisniewski M. Selective extraction of palladium (II) from hydrochloric acid solutions with phosphonium extractants // Separation and Purification Technology. 2010. V. 80. P. 385389.

15. Чекушин В.С., Борбат В.Ф. Экстракция благородных металлов сульфидами и сульфоксидами. М.: Наука, 1984. С. 152.

16. Huang Y., Tong Y., Wang C., Yang Y. Solvent extraction of palladium(II) with newly synthesized asymmetric branched alkyl sulfoxides from hydrochloric acid // RSC Advances. 2015. V. 5. No. 81. P. 1-8.

17. Katsuta S., Yoshimoto Y., Okai M., Takeda Y., Bessho K. Selective Extraction of Palladium and Platinum from Hydrochloric Acid Solutions by Trioctylammonium-Based Mixed Ionic Liquids // Industrial and Engineering Chemistry Research. 2011. V. 50. P. 12735-12740.

18. Sasaki Y., Morita K., Saeki M., Hisamatsu S., Yoshizuka K. Precious metal extraction by $\mathrm{N}, \mathrm{N}, \mathrm{N}^{\prime}, \mathrm{N}^{\prime}$-tetraoctylthiodiglycolamide and its comparison with $\mathrm{N}, \mathrm{N}, \mathrm{N}^{\prime}, \mathrm{N}^{\prime}$-tetraoctyldiglycolamide and methylimino-N, $\mathrm{N}^{\prime}$-dioctylacetamide // Hydrometallurgy. 2017. V. 169. P. 576-584.
19. Буслаева Т.М., Волчкова Е.В., Крылова Е.А., Громов С.П., Сидоренко Н. И. Экстракция благородных металлов макроциклическими соединениями // Известия вузов. Цветная металлургия. 2008. № 6. С. 30-37.

20. Belova V. V., Khol'kin A.I., Zhidkova T. I. Extraction of PlatinumGroup Metals from Chloride Solutions by Salts of Quaternary Ammonium Bases and Binary Extractants // Theoretical Foundations of Chemical Engineering. 2007. V. 41. No. 5. PР. 743-751.

21. Синтез комплексных соединений металлов платиновой группы. Справочник / Под ред. И. И. Черняева. М.: Наука, $1964.340 \mathrm{C}$

22. Рудик И.С., Катасонова О.В., Моходоева О.Б., Марютина Т.А., Спиваков Б.Я, Илюхин И.В. Разделение $\mathrm{Pt}(\mathrm{IV}), \mathrm{Pd}(\mathrm{II})$ и Rh(III) методом многоступенчатой экстракции из хлоридных растворов с применением азотсодержащих экстрагентов // Заводская лаборатория. Диагностика материалов. 2019. Т. 85 . № 4. C. 5-10.

23. Марютина Т. А. Применение градиента концентрации реагента в неподвижной фазе для разделения палладия(II) и родия(III) методом жидкостной хроматографии со свободной неподвижной фазой // Журн. аналит. химии. 2009. Т. 64. № 3. С. 309-312.

\section{References}

1. Analyticheskaya khimiya metallov platinovoy gruppy. [Analytical chemistry of platinum group metals. Collection of Review Articles]. Ed.Zolotov Yu.A., Varshal G. M., Ivanov V.M. M.: KomKniga Publ., 2005. 592 p. (in russ.)

2. Maryutina T.A., Fedotov P.S. Countercurrent Chromatography in Elemental Analysis: From Oil to High-Purity Substances // J. Anal. Chem. 2019. V. 74. P. 239-247.

3. Fedotov P.S., Kronrod V.A., Maryutina T.A., Spivakov B. Ya. Simulation of the mechanism of liquid stationary phase retention in a rotating coiled column: hydrophilic liquid systems // J. Anal. Chem. 2002. V. 57. No. 2. P. 145-149.

4. Countercurrent Chromatography: The Support-Free Liquid Stationary Phase // Comprehensive Analytical Chemistry (Ed.: Berthod A.). Amsterdam: Elsevier. 2002. V. 38

5. Satherland Y., Hewitson P., Ignatova S. New 18-1 process-scole counter-current chromatohraghy // Journal of Chromatograghy A. 2009. V. 1216. P. 4701-4205.

6. Nguyen T. N., Sonu C.H., Lee M.S. Separation of platinum(IV) and palladium(II) from concentrated hydrochloric acid solution by mixtures of amines with neutral extractants // Journal of Industrial and Engineering Chemistry. 2015. V. 32. P. 238-245.

7. Lee J-Y., J. Kumar R., Kim J-S, Kim D-J., Yoon H-S. Extraction and separation of $\mathrm{Pt}(\mathrm{IV}) / \mathrm{Rh}$ (III) from acidic chloride solutions using Aliquat 336 // Journal of Industrial and Engineering Chemistry. 2009. V. 15. P. 359-364.

8. Hoh Y.C., Chuang W.S., Yueh P.S. The Extraction of Platinum from Pt(II) Chloride Solution by a Quaternary Ammonium Compound // J. Chem. Tech. Biotechnol. 1985. V. 35A. P. 41-47.

9. Pasdar H., Saghavaz B.H., Fallah Z., Shahi M., Davallo M. Liquid-liquid extraction of palladium (II) in acids chloride solution using tri-n-octylamine // ASRJETS. 2017. V. 38. No. 1. P. 258264.

10. Jaree A., Khunphakdee N. Separation of concentrated platinum(IV) and rhodium(III) in acidic chloride solution via liquidliquid extraction using tri-octylamine // Journal of Industrial and Engineering Chemistry. 2011. V. 17. P. 243-247.

11. Mirza M.Y. Studies on the extraction of platinum metals with tri-iso-octylamine from hydrochloric and hydrobromic acid: 
separation and determination of gold, palladium and platinum // Talanta. 1980. V. 27(2). P. 101-106.

12. Costa M.C., Assunção A., Rosa da Costa A.M., Nogueira C., Paiva A.P. Liquid-liquid extraction of platinum from chloride media by $\mathrm{N}, \mathrm{N}$-dimetyl-N, N-dicyclohexyltetradecyl-malonamide // Solvent Extration and Ion Exchange. 2013. V. 31. P. 12-23.

13. Ortet O., Paiva A.P. Development of tertiary thioamide derivatives to recover palladium(II) from simulated complex chloride solutions // Hydrometallurgy. 2015. V. 151. P. 33-41.

14. Cieszynska A., Wisniewski M. Selective extraction of palladium (II) from hydrochloric acid solutions with phosphonium extractants // Separation and Purification Technology. 2010. V. 80. P. 385389.

15. Chekushin V.S., Borbat V.F. Ekstraktsiya blagorodnykh metallov sul'fidami i sul'foksidami [Extraction of precious metals by sulfides and sulfoxides]. M.: Nauka Publ., 1984. 152 p. (in russ).

16. Huang Y., Tong Y., Wang C., Yang Y. Solvent extraction of palladium(II) with newly synthesized asymmetric branched alkyl sulfoxides from hydrochloric acid // RSC Advances. 2015. V. 5. No. 81. P. 1-8.

17. Katsuta S., Yoshimoto Y., Okai M., Takeda Y., Bessho K. Selective Extraction of Palladium and Platinum from Hydrochloric Acid Solutions by Trioctylammonium-Based Mixed Ionic Liquids // Industrial and Engineering Chemistry Research. 2011. V. 50. P. 12735-12740.
18. Sasaki Y., Morita K., Saeki M., Hisamatsu S., Yoshizuka K. Precious metal extraction by $\mathrm{N}, \mathrm{N}, \mathrm{N}^{\prime}, \mathrm{N}^{\prime}$-tetraoctylthiodiglycolamide and its comparison with $\mathrm{N}, \mathrm{N}, \mathrm{N}^{\prime}, \mathrm{N}^{\prime}$-tetraoctyldiglycolamide and methylimino-N, $\mathrm{N}^{\prime}$-dioctylacetamide // Hydrometallurgy. 2017. V. 169. P. 576-584.

19. Buslaeva T.M., Krylova E. A., Volchkova E. V. et al. The extraction of noble metals by macrocyclic compounds // Russ. J. Non-ferrous Metals. 2008. V. 49. P. 459-465.

20. Belova V.V., Khol'kin A. I., Zhidkova T. I. Extraction of PlatinumGroup Metals from Chloride Solutions by Salts of Quaternary Ammonium Bases and Binary Extractants // Theoretical Foundations of Chemical Engineering. 2007. V. 41. No. 5. PP. 743-751.

21. Sintez kompleksnykh soyedineniy metallov platinovoy gruppy. Spravochnik. [The synthesis of complex compounds of platinum group metals. Directory]. Ed. I. I. Chernyaev. M.: Nauka Publ., 1964.340 p. (in russ.)

22. Rudik I. S., Katasonova O.V., Mokhodoeva O. B., Maryutina T. A., SpivakovB.Ya., Ilyukhin I.V. Separation of Pt (IV), Pd (II) and $\mathrm{Rh}$ (III) from chloride solutions by multistage solvent extraction using nitrogen-containing extractants // Industrial Laboratory. Diagnostics of Materials. 2019. V. 85. No. 4. P. 5-10.

23. Maryutina, T.A. Use of reagent concentration gradient in the stationary phase for the separation of palladium(II) and rhodium(III) by countercurrent chromatography // J. Anal. Chem. 2009. V. 64. P. 295-298.

\section{ВОДОРОД В УГЛЕРОДНЫХ НАНОСТРУКТУРАХ ДЛЯ АЭРОКОСМИЧЕСКИХ АППАРАТОВ}

Ученые ЦНИИчермет им. И. П. Бардина в рамках проекта РФФИ изучают взаимодействие атомарного водорода с углеродными нано- и микроструктурами. Реализация проекта станет важным шагом по развитию чистой энергетики для аэрокосмических аппаратов.

Работа космических аппаратов, самолетов и беспилотников на водородном топливе безопасна для природы - это экологически чистый энергоноситель. Но хранить и транспортировать водород в газообразном состоянии сложно (в композитных резервуарах под высоким давлением), а в виде криогенной жидкости - затратно. Более выгодно и безопасно - в твердом виде, интеркалируя водород высокой плотности в углеродные наноструктуры.

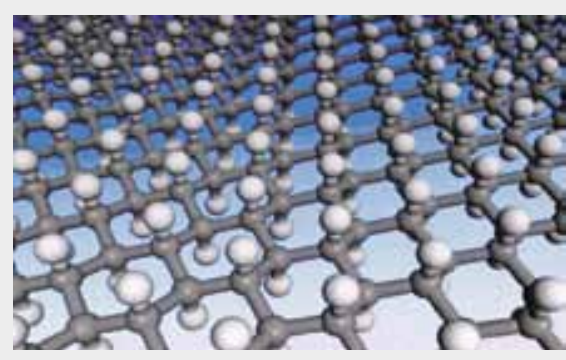

В рамках гранта РФФИ ученые ЦНИИчермет им. И. П. Бардина исследуют взаимодействие водорода с мультислойными графеновыми структурами (в том числе графеновой бумагой), так называемым расширенным наноструктурированным графитом, графитовыми нановолокнами, многослойными углеродными нанотрубками и углеродными лукообразными наноструктурами. Это поможет определить эффективные способы хранения водорода для использования в топливных элементах в летательных аппаратах.

Чтобы изучить характеристики и механизмы сорбции и интеркаляции водорода в углеродных нано- и микроструктурах, ученые гидрировали их в водородной плазме. В ходе исследования раскрыли физику изучаемых процессов и развили эффективную методику обработки и анализа термодесорбционных спектров водорода для углеродных образцов. Также получила развитие термодинамическая теория эффекта Курдюмова (термоупругое равновесие фаз для сталей) и водородного спилловер-эффекта, проявляющихся при интеркаляции водорода высокой плотности в наноуглеродные структуры.

Ученые проведут термодинамическое изучение большого массива экспериментальных данных различных авторов о диффузии, сорбции и интеркаляции водорода в эпитаксиальных графенах и определят энергетические характеристики механизмов химических взаимодействий водорода с поверхностями и границами раздела в наноуглеродных системах. Результатом исследований должно стать создание фундаментальной основы для развития прорывной технологии эффективного и безопасного хранения водорода в углеродных наноматериалах. Предстоит определить перспективы ее применения в топливных элементах в аэрокосмических аппаратах.

Денис Овчаренко, пресс-секретарь

ГНЦ ФГУП «ЦНИИчермет им. И. П. Бардина» dvovcharenko@chermet.net www.chermet.net 